\title{
Hydrofluoric acid etching versus self-etching glass ceramic primer: consequences on the interface with resin cements
}

\author{
Geneviève Grégoire ${ }^{1 *}$, Pierre-Pascal Poulet ${ }^{2}$, Patrick Sharrock ${ }^{3}$, Florent Destruhaut ${ }^{2}$ and Bruno Tavernier ${ }^{4}$ \\ ${ }^{1}$ Faculty of Odontology, University Toulouse III, and University Paris Descartes, France \\ ${ }^{2}$ Faculty of Odontology, University Toulouse III, France \\ ${ }^{3}$ CNRS UMR 5302, University Toulouse III, Mines-Albi, Albi, France \\ ${ }^{4}$ Faculty of Odontology, University Paris Diderot, and Rothschild Hospital AP-HP, Paris, France
}

\begin{abstract}
Objectives: The purpose of this in vitro study was to compare the effects of traditional HF + silane (two steps process) versus self-etching glass ceramic primer (one step process) on the wettability of 2 types of CAD/CAM glass ceramics and the chemical bonding types between the ceramics and a composite cement. The tested ceramics were a leucite-reinforced feldspathic glass ceramic (IPS Empress CAD Multi) and a lithium disilicate-based glass ceramic (IPS e.max CAD).

Methods and materials: Forty specimens $(18 \mathrm{~mm}$ x $4 \mathrm{~mm}$ ) were fabricated, twenty from each glass ceramic then sanded to alumina of $50 \mu \mathrm{m}$ under reduced pressure of 1 bar. Each group of 20 was randomly sub divided into two groups ( $n=10)$ : Group 1 = IPS Empress CAD Multi + MEP(self-etching ceramic primer Monobond Etch\&Prime, Ivoclar

Vivadent); Group 2 = IPS Empress CAD Multi + 5.0\% HF (IPS Ceramic Etching Gel, Ivoclar Vivadent) + MP (Monobond Plus, Ivoclar Vivadent); Group 3 = IPS e.max CAD + MEP; Group $4=$ IPS e.max CAD + 5.0\% HF + MP. The effect of the different surface treatments applied to the glass ceramics was compared by analysis of water contact angle measurements as well as spreading coefficients. Contact angles were determined with a Digidrop device (GBX). Contact angles and spreading coefficients for ceramics with different surface treatments were compared by ANOVA. A second analysis of variance was made to compare the two glass ceramics with identical treatments. Statistical analysis also included the Duncan post hoc test ( $p<0.05)$. Eight additional specimens for infrared spectroscopy were assigned, four for each glass ceramic. The discs were cut longitudinally and each half received a surface treatment. After each surface treatment, a resin cement (Multilink Automix, Ivoclar Vivadent) was applied to the surface of the half-disks and photopolymerized. The samples were examined on their slice (treated ceramic + resin cement) by spectrophotometric analysis. FTIR, by peak recognition and spectral comparison, allowed to reveal the bonding types formed between the ceramic after surface treatments and the resin cement. A differential analysis was carried out to compare the spectra obtained with the 2 treatments of each of the ceramics and to highlight any differences.
\end{abstract}

Results: The values of the contact angles were more favorable with HF treatment followed by MP for the two glass ceramics, the same applied to the values of the spreading coefficients (negative values). These results were even more pronounced for the IPS Empress CAD Multi. Infrared spectra of the interfaces between the two treated ceramics and the resin cement showed chemical bonds. The treatment with HF + MP increased binding more than treatment with MEP, particularly for IPS Empress CAD Multi.

Conclusion: Wettability of the glass ceramics depended on surface treatment, and the ceramic structure was related to the bonding of the silane to the resin cement. This means it is important to select surface treatment as a function of ceramic material. Strong, hydrophobic interactions play an important role in the long-term durability of bonding in cement-ceramic associations.

\section{Clinical relevance statement}

Clinicians need to know the effectiveness of different surface treatments of CAD-CAM ceramics to optimize the interfaces of their prostheses.

\section{Introduction}

The long-term survival of aesthetic restorations remains a challenge dependant on successful and reliable bonding of ceramics to dental substrate. In order to improve resin cement bonding to ceramics, various surface treatments favoring micromechanical retention and chemical bonding were recommended [1,2]. According to CekikNagas, the composition of the ceramic determines the best surface treatment to be applied [3].

A vast number of previous works have investigated the effect of etching protocols on glassmatrix ceramics. Acid etching of the bonding surface of glass ceramic restorations is considered as the most effective treatment method. Selective removing of the glassy matrix of silicate ceramics results in a micromorphological three-dimensional porous surface that allows micromechanical interlocking of the luting composite $[4,5]$. The effects of acid etching depend on the acid type and its concentration, the etching time and the ceramic type being treated.

${ }^{*}$ Correspondence to: Geneviève GRÉGOIRE, Faculté de Chirurgie Dentaire, 3 chemin des Maraîchers Toulouse, France, Tel: +33 (0)5 621729 29; E-mail: genevieve.gregoire@univ-tlse3.fr

Key words: glass ceramics, surface treatment, contact angles, chemical bonding, hydrofluoric acid, self-etching ceramic primer

Received: May 30, 2019; Accepted: June 06, 2019; Published: June 10, 2019 
The hydrofluoric acid (HF) is the most frequently used acid [6-8]. But the acidulated phosphate fluoride (APF) and the ammonium hydrogen difluoride $(\mathrm{ADF})$ are also used.

The ammonium hydrogen difluoride, in reaction with silica matrix creates some silicon tetrafluoride and ammonium fluoride. This acid may be used as a glass etchant or as an intermediate for the production of hydrofluoric acid [5,9].

Hydrofluoric acid etching followed by silanization generates higher bond strengths than either treatment alone. Silanization is understood to create hydrogen bonding and covalent bonding between the resin and the ceramic and increased wettability of the ceramic surface while etching provides the mechanical interlocking [4,9]. The chemical adhesion produced by silane promoted higher mean bond strength values than the micromechanical retention produced by any etchant [10].

Recently, a simplified acid ceramic primer has been introduced, claiming to perform a mild acid etching (very smooth etching pattern) and silanize using a single solution [11]. This onebottle system, Monobond Etch\&Prime (MEP), combining ammonium polyfluoride and silane based on trimethoxypropyl methacrylate leaves a chemically bonded thin layer. It was introduced to simplify the bonding procedure by etching and priming glass ceramics in a one step process. Ammonium polyfluoride has milder acidity in comparison to hydrofluoric acid, which is expected to result in weaker etching pattern.

Several authors have published studies comparing the efficiency of the protocol using this new system with 2-step surface treatments using hydrofluoric acid at concentration and application times determined followed by silane [12-17]. Their studies gave comparative results on shear bond strengths, field-emission scanning electron microscope (FESEM) analyzes, contact angle and micromorphological analyses, tensile bond strength.

The purpose of this in vitro study was to compare the effects of traditional HF + silane (two steps process) versus self-etching glass ceramic primer (one step process) on the wettability of 2 types of CAD/ CAM glass ceramics and the chemical bonding between the ceramics and a composite cement. The tested ceramics were a leucite-reinforced feldspathic glass ceramic (IPS Empress CAD Multi) and a lithium disilicate-based glass ceramic (IPS e.max CAD).

\section{Methods and materials}

The ability for bonding to the ceramics and the different surface treatments proposed were investigated by comparing the resulting surface energies obtained [18]. The interfaces between treated ceramic and resin cement were examined by Fourier Transform Infrared spectroscopy (FTIR).

\section{Surface energy of two CAD-CAM glass ceramics after different surface treatments}

The surface treatments selected for the glass ceramics were acids and silanes [19-22]. Forty specimens (18 $\mathrm{mm}$ diameter $\mathrm{x} 4 \mathrm{~mm}$ height) were fabricated, sanded to alumina of $50 \mu \mathrm{m}$ under reduced pressure of 1 bar, twenty from each glass ceramic (Table 1). Each group of 20 was thereafter randomly divided into two groups $(n=10)$ according to the surface treatments:

Group 1: IPS Empress CAD Multi treated with Monobond Etch\&Prime (MEP) with scrubbing motion for 20 seconds, waiting for 40 seconds, rinsed and dried for 10 seconds.

Group 2: IPS Empress CAD Multi treated with IPS Ceramic Etching Gel (Table 1) (5\% HF) for 60 seconds, rinsed, applied Monobond Plus (MP) for 60 seconds, dried.

Group 3: IPS e.max CAD treated with MEP with scrubbing motion for 20 seconds, waiting for 40 seconds, rinsed and dried for 10 seconds.

Group 4: IPS e.max CAD treated with 5\% HF for 20 seconds, rinsed, applied MP for 60 seconds, dried.

The effect of the different surface treatments applied to the glass ceramics was compared by analysis of water contact angle measurements as well as spreading coefficients.

Contact angles were determined with a Digidrop device (GBX) using a graduated micro syringe to place $10 \mu \mathrm{l}$ drops on the surfaces to be analyzed. At equilibrium, the right and left contact angles and

Table 1. Materials, composition of products used in this study

\begin{tabular}{|c|c|c|c|c|}
\hline Material and Manufacturer & \multicolumn{3}{|l|}{ Composition } & Batch Number \\
\hline $\begin{array}{l}\text { IPS Empress CAD Multi } \\
\text { LT C2 } \\
\text { (IvoclarVivadent; Schaan, } \\
\text { Liechtenstein) }\end{array}$ & \multicolumn{3}{|l|}{$\begin{array}{l}\mathrm{SiO}_{2}(60-65 \% \mathrm{wt}), \mathrm{Al}_{2} \mathrm{O}_{3}(16-20 \% \mathrm{wt}), \mathrm{K}_{2} \mathrm{O}(10-14 \% \mathrm{wt}) \\
\mathrm{Na}_{2} \mathrm{O}(3.5-6.5 \% \mathrm{wt}) \text {, other oxides }(0.5-7 \% \mathrm{wt}) \text {, pigments }(0.2-1 \mathrm{wt})\end{array}$} & L30050 \\
\hline $\begin{array}{l}\text { IPS e.max CAD } \\
\text { LT A2 } \\
\text { (IvoclarVivadent; Schaan, } \\
\text { Liechtenstein) }\end{array}$ & \multicolumn{3}{|l|}{$\begin{array}{l}\mathrm{SiO}_{2}(57-80 \% \mathrm{wt}), \mathrm{Li}_{2} \mathrm{O}(11-19 \% \mathrm{wt}), \mathrm{K}_{2} \mathrm{O}(0-13 \% \mathrm{wt}), \mathrm{P}_{2} \mathrm{O}_{5} \\
(0-11 \% \mathrm{wt}), \mathrm{ZrO}_{2}(0-8 \% \mathrm{wt}), \mathrm{ZnO}(0-8 \% \mathrm{wt}), \mathrm{Al}_{2} \mathrm{O}_{3}(0- \\
5 \% \mathrm{wt}), \mathrm{MgO}(0-5 \% \mathrm{wt}), \text { colouring oxides }(0-8 \% \mathrm{wt})\end{array}$} & W89190 \\
\hline $\begin{array}{l}\text { IPS CeramicEtching Gel } \\
\text { (IvoclarVivadent; Schaan, } \\
\text { Liechtenstein) }\end{array}$ & \multicolumn{3}{|l|}{ Hydrofluoric acid (5\%wt) } & L54951 \\
\hline $\begin{array}{l}\text { Monobond Plus } \\
\text { (IvoclarVivadent; Schaan, } \\
\text { Liechtenstein) }\end{array}$ & \multicolumn{3}{|c|}{$\begin{array}{l}\text { 3-trimethoxysilylpropyl methacrylate }(\leq 2.5 \% \mathrm{wt}) \text {, methacrylated phosphoric acid ester }(\leq 2.5 \% \mathrm{wt}) \text {, disulfide } \\
\text { diméthacrylates ethanol }(96 \% \mathrm{wt})\end{array}$} & V02683 \\
\hline $\begin{array}{l}\text { Monobond Etch \& Prime } \\
\text { (IvoclarVivadent; Schaan, } \\
\text { Liechtenstein) }\end{array}$ & \multicolumn{3}{|c|}{$\begin{array}{l}\text { Tetrabutyl ammonium dihydrogen trifluoride, methacrylated phosphoric acid ester, trimethoxysilylpropyl methacrylate, } \\
\text { butanol, ethanol, water, pigments }\end{array}$} & U12505 \\
\hline \multirow[b]{2}{*}{$\begin{array}{l}\text { MultilinkAutomix } \\
\text { (IvoclarVivadent; Schaan, } \\
\text { Liechtenstein) }\end{array}$} & & Base \% wt & Catalyst \% wt & \\
\hline & $\begin{array}{l}\text { Dimethacrylates and HEMA, barium glass filler } \\
\text { Ba-Al-Fluoro-Silicate glass, ytterbium trifluoride, highly dispersed silica, } \\
\text { catalysts and stabilizer, pigments }\end{array}$ & $\begin{array}{l}33.1 \\
37.4 \\
23.0 \\
5.4 \\
1.0 \\
<0.03\end{array}$ & \begin{tabular}{|l}
32.4 \\
37.4 \\
23.0 \\
5.4 \\
1.8 \\
-
\end{tabular} & V10222 \\
\hline
\end{tabular}


the average were calculated by the GBX software; each contact angle was measured five times for the liquid at room temperature $\left(22^{\circ} \mathrm{C}\right)$. The software also calculates the spreading coefficient $S$ for each measurement. Water was used for contact angle measurements on glass ceramic specimens. Its surface tension is $72.8 \mathrm{~mJ} / \mathrm{m}^{2}$. The measurement was made at 60 seconds after contact of ceramic and water.

Contact angles ( $\theta$ in degrees) and spreading coefficients ( $\mathrm{S}$ in $\mathrm{mJ} /$ $\mathrm{m}^{2}$ ) for ceramics with different surface treatments were compared by ANOVA. A second analysis of variance was made to compare the two glass ceramics with identical treatments. The Duncan post hoc test $(\mathrm{p}<$ 0.05 ) was used to find any statistically significant differences between groups.

The $\mathrm{pH}$ values for HF (IPS Ceramic Etching Gel), MP and MEP were evaluated with a model 210 pHmeter from Hanna instruments, (Woonsocket, Rhode Island, USA) and repeated three times. The $\mathrm{pH}$ value is a significant element of the aggressiveness of the acid

\section{Infrared Spectroscopy of materials and interfaces}

The FTIR spectra of materials used in this study (resin cement, MEP, MP) were recorded with a Mattson Genesis II spectrometer (Thermoelectron France) from 400 to $4000 \mathrm{~cm}^{-1}$.

Eight additional specimens ( $18 \mathrm{~mm}$ diameter $\mathrm{x} 4 \mathrm{~mm}$ height) were fabricated, sanded to alumina of $50 \mu \mathrm{m}$ under reduced pressure of 1 bar, four from each glass ceramic (Groups $1 b$ and $2 b$ for IPS Empress CAD Multi, Groups $3 \mathrm{~b}$ and $4 \mathrm{~b}$ for IPS e.max CAD). The ceramic discs were cut longitudinally in 2 (Figure 1) using a low speed saw (IsoMet, Buehler Ltd, Evanston, USA) equipped with a diamond disc (102 mm x $0.3 \mathrm{~mm}$ series 15 LC Diamond,

Buehler Ltd, Evanston, USA. The specimens were treated as described previously: Groups $1 \mathrm{~b}$ and $3 \mathrm{~b}$ with MEP, Groups $2 \mathrm{~b}$ and $4 \mathrm{~b}$ with $5 \% \mathrm{HF}$ and MP. After each surface treatment, a resin cement (Multilink Automix, Ivoclar Vivadent) was applied to the surface of the halfdisks and then photopolymerized for 20 seconds with the lamp of intensity $1000 \mathrm{~mW} / \mathrm{cm}^{2}$ (SmartLite, Dentsply). The samples were examined on their slice by spectrophotometric analysis (treated ceramic + resin cement). The flat slices of the half-discs were placed directly on the face of the diamond. FTIR, by peak recognition and spectral comparison, allowed to reveal the bonding patterns formed between the ceramic after surface treatments and the resin cement. A differential analysis was carried out to compare the spectra obtained with the 2 treatments of each of the ceramics and to highlight any differences.

\section{Results}

Surface energy of two CAD-CAM glass ceramics with different surface treatments Average values of measured contact angles and spreading coefficients obtained between ceramic surface and liquid test (water) at 60 seconds (Table 2):

- for leucite-reinforced feldspathic glass ceramic (IPS Empress CAD Multi), the angles obtained for Group 2 (treated with HF + MP)

Table 2. Means and standard deviation for contact angle values $\left(\theta^{\circ}\right)$ and spreading coefficient values $\left(\mathrm{S} \mathrm{mJ} / \mathrm{m}^{2}\right)$ obtained for tested ceramics with different treatments, at time 60 seconds Differences between groups expressed as a percentage.

\begin{tabular}{|c|c|c|c|}
\hline & Hydrofluoric acid Monobond Plus & Monobond Etch\&Prime & Difference between groups \\
\hline & \multicolumn{3}{|l|}{ IPS Empress CAD Multi } \\
\hline & Group 1 & Group 2 & Group 2 / Group 1 \\
\hline Contact angle $\Theta\left({ }^{\circ}\right)$ & $44.6(1.0)$ & $74.2(2.0)$ & $+66.4 \%$ \\
\hline \multirow[t]{3}{*}{ Spreading coefficient $\mathrm{S}\left(\mathrm{mJ} / \mathrm{m}^{2}\right)$} & $-21.20(1.39)$ & $-53.28(3.80)$ & $+151.3 \%$ \\
\hline & \multicolumn{3}{|l|}{ IPS e.max CAD } \\
\hline & Group 3 & Group 4 & Group 4 / Group 3 \\
\hline Contact angle $\Theta\left({ }^{\circ}\right)$ & $51.6(0.1)$ & $62.5(0.7)$ & $+21.1 \%$ \\
\hline Spreading coefficient $\mathrm{S}\left(\mathrm{mJ} / \mathrm{m}^{2}\right)$ & $-27.56(0.66)$ & $-39.22(0.84)$ & $+42.3 \%$ \\
\hline
\end{tabular}

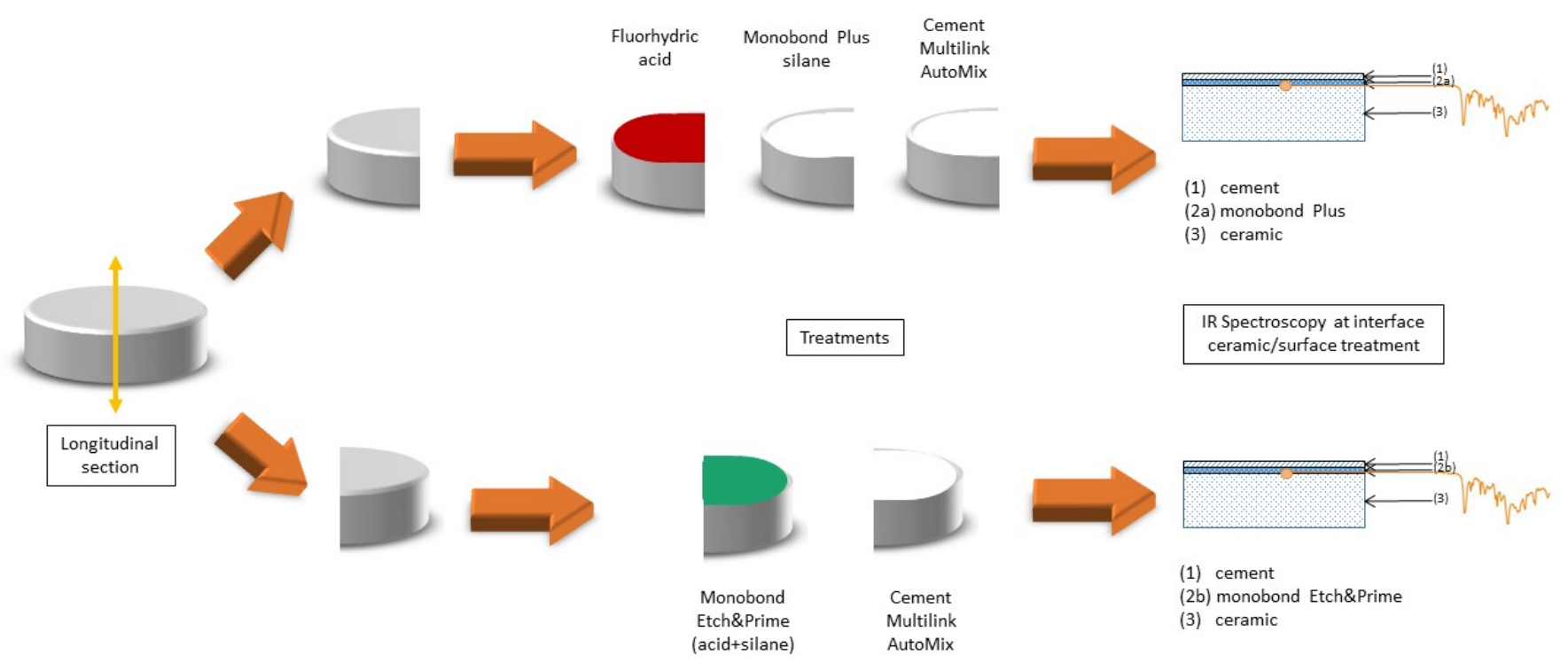

Figure 1. Schemating drawing of the ceramic samples, treatments and spectroscopy. 
were lower than those obtained for Group 1 (treated with MEP) and it is known that a low contact angle means a better interaction between two phases and a more complete wetting of the liquid. We noted that the spreading coefficients obtained for Group 2 were closer to zero than those obtained for Group 1. This means that the treatment with $\mathrm{HF}$ followed by the application of the silane provides a better coefficient of spreading.

- for lithium disilicate-reinforced glass ceramic (IPS e.max CAD), the angles obtained for Group 4 (treated with HF + MP) were lower than those obtained for Group 3 (treated with MEP). We noted that the spreading coefficients obtained for Group 4 were closer to zero than those obtained for Group 3.

The values of the contact angles were more favorable with HF treatment followed by MP for the two glass ceramics, the same applied to the values of the spreading coefficients (negative values). These results were even more pronounced for the IPS Empress CAD Multi.

Regardless of the surface treatment on IPS Empress CAD Multi, the results obtained with Groups 1 and 2 were statistically different for contact angles $(\mathrm{F}=543.235, \mathrm{p}<0.05)$ as well as for the spreading coefficients $(\mathrm{F}=189.690, \mathrm{p}<0.05)$. The results obtained on IPS e.max CAD with Groups 3 and 4 were statistically different for the contact angles $(\mathrm{F}=456.96, \mathrm{p}<0.05)$ as well as for the spreading coefficients $(\mathrm{F}$ $=236.273, \mathrm{p}<0.05)$.

If we compare the results of the two ceramics after the self-etching glass ceramic primer, it can be notedthat Groups 1 (IPS Empress CAD Multi) and 3 (IPS e.max CAD) had a significant difference for the contact angles $(\mathrm{F}=58.630, \mathrm{p}<0.05)$ as well as for spreading coefficients $(\mathrm{F}=24.467, \mathrm{p}<0.05)$. The comparison after HF treatment followed by silanization, Groups 2 (IPS Empress CAD Multi) and 4 (IPS e.max
CAD) showed a significant difference, whether for contact angles ( $\mathrm{F}$ $=88.84, \mathrm{p}<0.05)$ or for spreading coefficients $(\mathrm{F}=33.671, \mathrm{p}<0.05)$.

The different surface treatments performed on both ceramics gave significantly different results. The Duncan post hoc test showed that there were four distinct groups ( $a, b, c, d)$, for contact angles and spreading coefficients.

The observed $\mathrm{pH}$ values were 2.0 for IPS Ceramic Etching Gel, 3.8 for MEP and 3.2 for MP.

They showed that the most concentrated acid was found in IPS Ceramic Etching Gel.

\section{Interaction between treated glass ceramics and resin cement}

Analysis of the FTIR spectrum of MEP showed mainly a large and strong band (3400-3330 $\left.\mathrm{cm}^{-1}\right)$ corresponding to silanol groups, as well as sharps but weak bands $\left(2950-2872 \mathrm{~cm}^{-1}\right)$ of C-H bonds of Si-O-alkyl, [23-25] (Figure 2a).

The FTIR spectrum of MP showed C-H bonds of methyl groups bands located at 2950- $2872 \mathrm{~cm}^{-1}$, and a strong characteristic band of $\mathrm{O}^{-\mathrm{CH}_{3}}$, near $1190 \mathrm{~cm}^{-1}[23,24]$ (Figure 2b).

The resin cement (Figure 3) had bands related to the acrylate group which will serve as "markers" in the analysis of the interfaces. We noted the presence of bands corresponding to symmetrical and asymmetric stretching of alkyl group located at $2872 \mathrm{~cm}^{-1}-2959 \mathrm{~cm}^{-1}$; characteristic bands of acrylate group $(\mathrm{C}=\mathrm{O})$ located around $1715 \mathrm{~cm}^{-1}$; bands located at $1296 \mathrm{~cm}^{-1}$ corresponding to C-H of the Si-R $[25,26]$.

For Group 1b (IPS Empress CAD Multi treated with MEP), 1 step process, (Figure $4 \mathrm{a}$ ), the strong and broad band around $3400-3300 \mathrm{~cm}^{-1}$ noted for MEP was no longer present, the $\mathrm{O}-\mathrm{H}$ and/or $\mathrm{NH}$ signals were

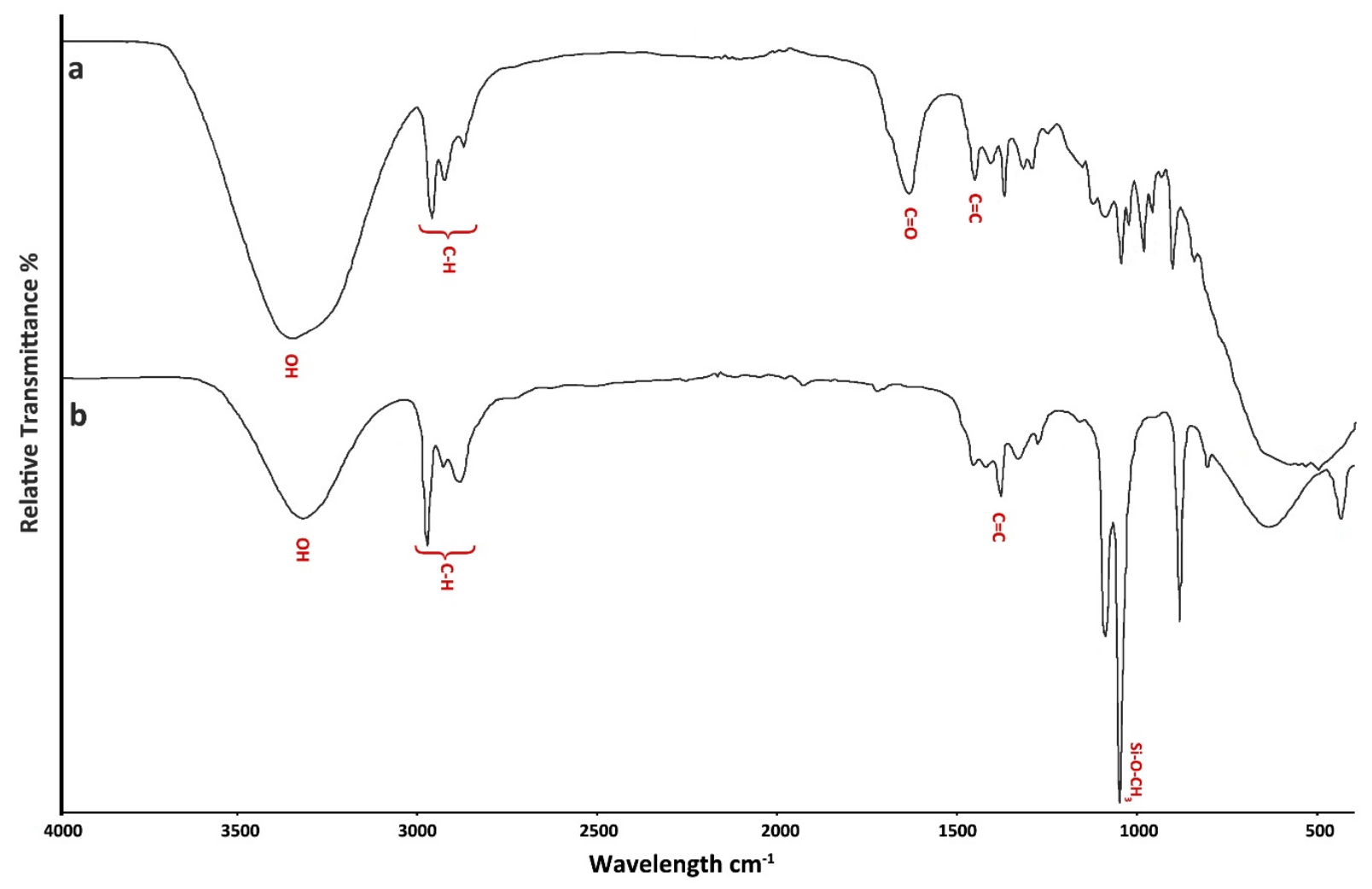

Figure 2. Infrared spectrum of treatment agents. a: Monobond Etch\&Prime; b: Monobond Plus 


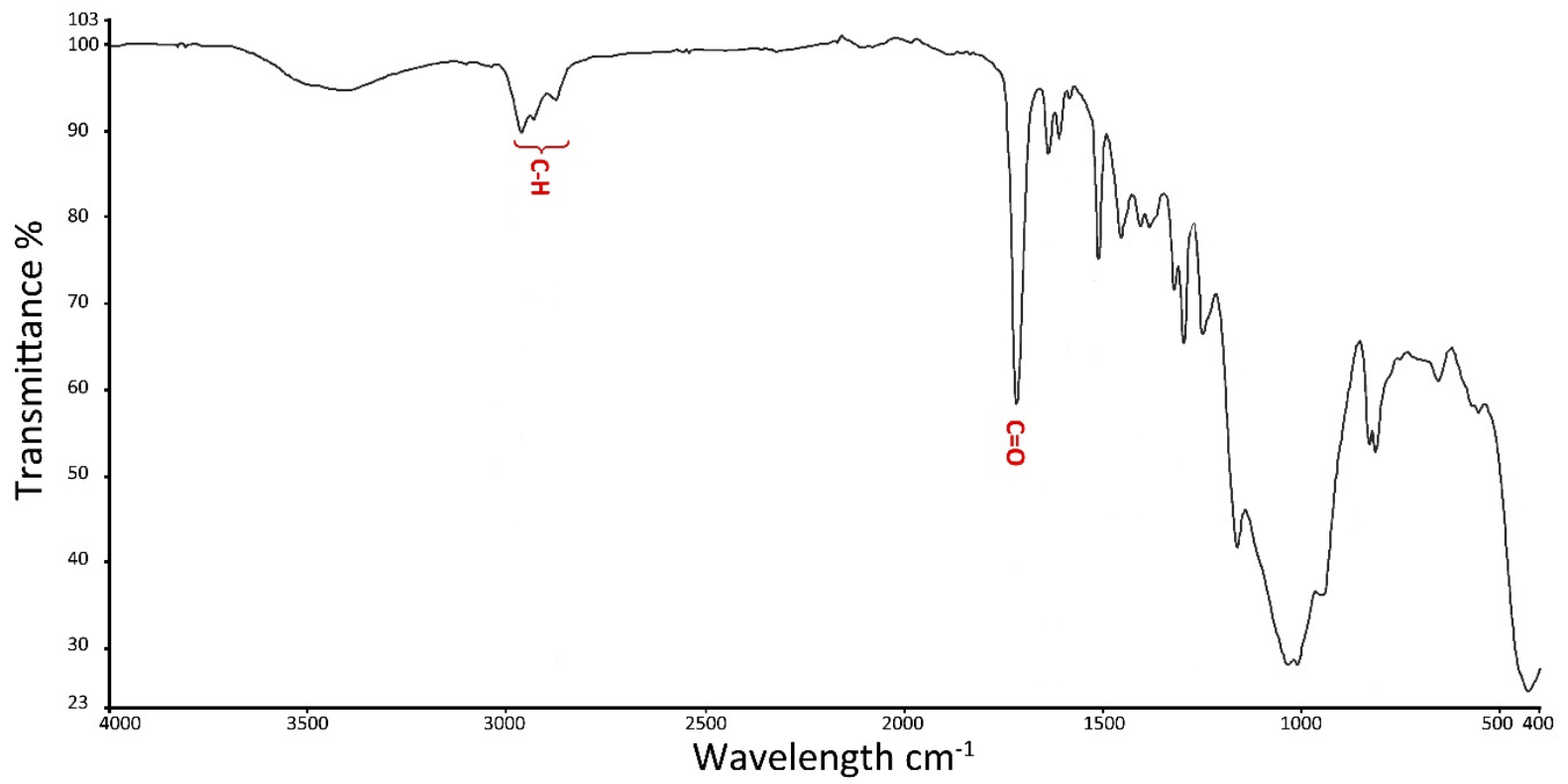

Figure 3. Infrared spectrum of resin cement, Multilink Automix

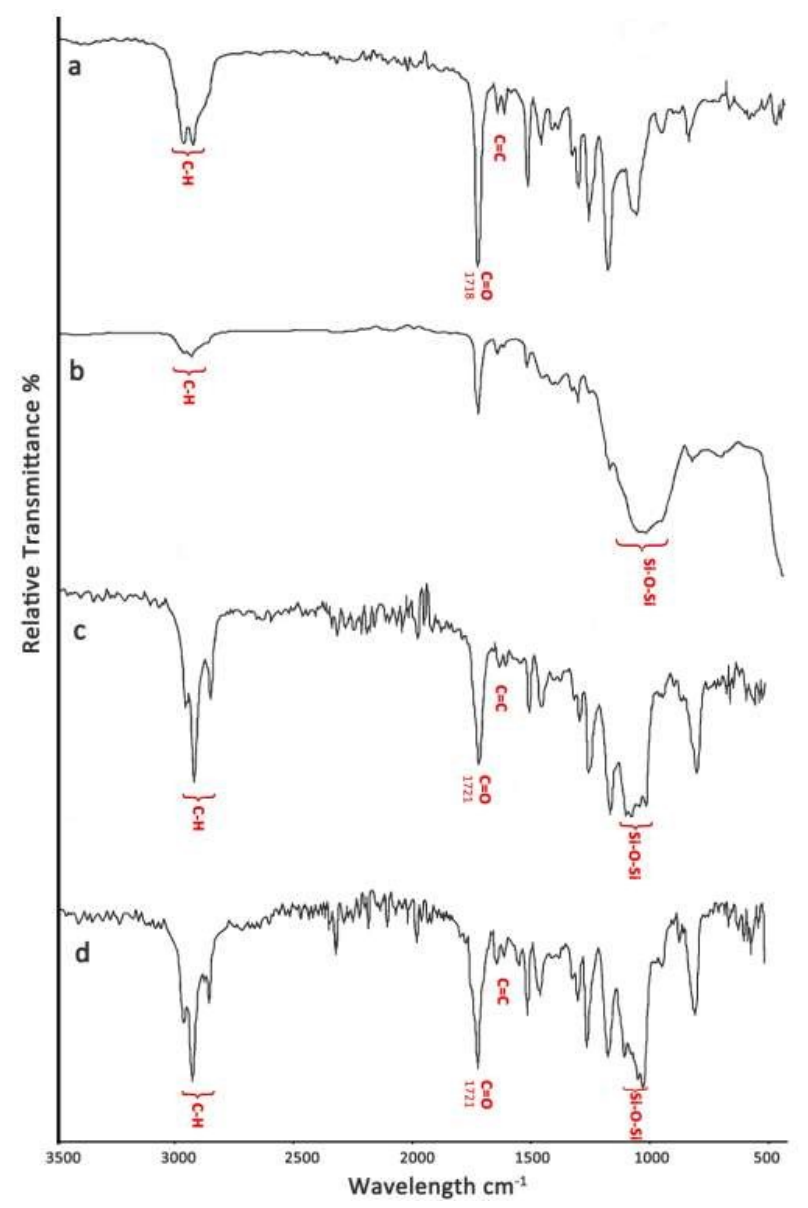

Figure 4. Infrared spectra of IPS Empress CAD Multi and IPS e.max CAD glass ceramic interfaces treated according to the 2 types of surface treatment with the resin cement: a: IPS Empress CAD Multi + MEP + resin cement; b: IPS Empress CAD Multi + HF + MP+ resin cement; c: IPS e.max CAD + MEP + resin cement; d: IPS e.max CAD + HF + MP + resin cement. (MEP: Monobond Etch\&Prime; HF: hydrofluoric acid; MP: Monobond Plus) 
also absent. Broadening of $\mathrm{C}-\mathrm{H}$ bands occurred and various multiple vibrations were observed in the "fingerprint " region between 1200 and $500 \mathrm{~cm}^{-1}$.

For Group 2b (IPS Empress CAD Multi treated with HF and MP), 2 steps process, (Figure $4 \mathrm{~b}$ ), dehydration was observed and low intensity bands appeared near 2900-2800 $\mathrm{cm}^{-1}$ (ethyl groups of resin cement and of MP). A neoformed matrix with large and broad absorption formed around $1000 \mathrm{~cm}^{-1}$.

For Group 3b (IPS e.max CAD treated with MEP), 1 step process, (Figure 4c), the large band in the zone $3400-3300 \mathrm{~cm}^{-1}$ noted for MEP was absent and three bands typical of C-H vibrations at 2950, 2923 et $2854 \mathrm{~cm}^{-1}$ were clearly seen.

For Group 4b (IPS e.max CAD treated with HF and MP), 2 steps process, (Figure $4 \mathrm{~d}$ ), the characteristic bands of the methacrylate monomers and HEMA of resin cement, $\mathrm{C}=\mathrm{O}$ located at 1721 and 1636 $\mathrm{cm}^{-1}$, were sharp.

\section{Discussion}

The interaction between a resin cement and a ceramic is determined by the capacity the cement has to wet the ceramic surface, as a function of the surface chemistry and roughness of the ceramic, as well as by the viscosity and composition of the resin cement [27].

In this work we investigated the wettability obtained with two surface treatment protocols on two ceramics. The surface treatment provided the combined effects from MEP vs HF + MP. Hydrofluoric acid (HF) treatment is commonly used on silica-based ceramics to react with, and remove, the glassy matrix that contains silica. This leaves the crystalline phase exposed, generating surface roughness. This process also results in enhanced wettability and surface energy on the ceramic surface $[28,29]$. Hydrofluoric acid etching of feldspathic and lithium disilicate ceramics, followed by priming with a silane coupling agent has been considered as the gold standard for the treatment of the silica-based ceramics [30]. Etching with hydrofluoric acid leads to preferential dissolution of one of the glassy phases of porcelain to create an appropriate microstructure for bonding. Meanwhile, the application of a silane coupling agent to the pretreated ceramic surface provides a chemical bond that is a major factor in creating a sufficient resin bond to silica-based ceramics. This treatment protocol offers the opportunity of improved micromechanical retention and/or increased physical interactions and wettability with the luting resin material, which is generally hydrophobic in nature [19].

HF increases chemical binding on the ceramic by inducing polarity which promotes surface hydrophilicity [31]. Murillo-Gomez, et al. [16] in an experiment on the effect of acid etching of ceramics determined that MEP produced smoother etching patterns and lower roughness values (comparable to untreated specimens) than any other protocol employing HF. This may be attributed to the fact that this primer, instead of common $\mathrm{HF}$, uses tetrabutylammonium dihydrogen trifluoride as etching agent [32]. This ammonium polyfluoride salt is an acidic compound used in industry to etch silica-based surfaces and it has a softer etching potential than HF [13]. Prado Lopes, each concluded in their work on HF etching followed by a silane solution that higher bond strengths were obtained than with MEP, the selfetching ceramic primer $[14,15]$. Such results confirm our observations on the surface structures noted with lower contact angles obtained for Groups 1 and 3 (treated with HF followed by silane) compared to results for Groups 2 and 4 (treated with MEP). Smaller contact angles reflect stronger interaction between two phases and more complete wettability with liquids. We also find that spreading coefficients for Groups 1 and 3 are closer to zero than the values obtained for Groups 2 and 4 . This signifies that treatment with HF followed by the silane gives the optimum spreading coefficient, in agreement with results of Stawarczyk and Sattabanasuk [27,33]. Together with ceramic wettability, microstructure and chemical composition, silane treatment influences the quality of the bonds to resin cements. Peumans showed that the different adhesion values found for the bonding of glass ceramics to adhesive cements are mostly due to the modifications of the structure by acid priming [34].

Infrared spectra of the interfaces between the two treated ceramics and the resin cement show bonding patterns. These interactions exist thanks to the silane intermediation that leads to stronger and stable bonds between the bonding components [34-36].

Comparing the spectra in Figures $4 \mathrm{a}$ and $4 \mathrm{~b}$, a broad matrixlike strong absorption formed in $4 \mathrm{~b}$. These intra and extramolecular absorptions reveal multiple bonding whereas in Figure $4 \mathrm{a}$, more individual and better-defined peaks show independent molecules. For IPS e.max CAD, comparing Figures $4 \mathrm{c}$ and $4 \mathrm{~d}$ shows that whatever the silananization, there are bonds between resin cement and the silanized ceramic with independent and well-defined $\mathrm{C}-\mathrm{H}$ vibrations. With both silanes, a strong siloxane bond remains. The previously hydrophilic surface becomes hydrophobic by formation of this surface complex [2]. For HF/MP the bands related to acrylate groups $(\mathrm{C}=\mathrm{O})$ and $(\mathrm{C}$ $=\mathrm{C}$ ) of the cement are more intense than for the MEP treatment. For the two ceramics, after joining, the hydrolysed methoxy groups do not form hydrogen bonds with water, but insoluble associations with other silane components [37]. Such strong, hydrophobic interactions play an important role in the long-term durability of bonding in cementceramic associations [36].

As treating materials are mainly composed by glassy phase, using strong etching protocols may damage materials internal microstructure, possibly affecting their mechanical performance, even more in the case of thin restorations as veneers. Future investigations must confirm the extent of these findings on materials mechanical properties in order to preserve their structural integrity [16].

\section{Conclusion}

Within the limitations of this in vitro study, the following conclusions can be drawn:

1 the values of the contact angles were more favorable with HF treatment followed by silanization versus self-etching glass ceramic primer treatment for the two glass ceramics. These results were even more pronounced for the leucite-reinforced feldspathic glass ceramic.

2 infrared spectra of the interfaces between the two treated ceramics and the resin cement showed bonding types. The treatment with hydrofluoric acid followed by silanization increased multi-bonding more than treatment with a self-etching glass ceramic primer, particularly for the leucite-reinforced feldspathic glass ceramic.

\section{Acknowledgments}

We thank Marie-Paule Lacomblet and Dr Mariné Petrossian, Dr Marwa Mbarki for experimental help and discussions. We thank also Ivoclar Vivadent for the kind support of the materials used in the study. 


\section{Conflict of interest}

\author{
None
}

\section{Funding}

This research did not receive any specific grant from funding agencies in the public, commercial, or not-for-profit sectors.

\section{References}

1. Elsaka SE (2014) Bond strength of novel CAD/CAM restorative materials to selfadhesive resin cement: the effect of surface treatments. J Adhes Dent 16: 531-540. [Crossref]

2. Lise DP, Perdigão J, Van Ende A, Zidan O, Lopes GC (2015) Microshear bond strength of resin cements to lithium disilicate substrates as a function of surface preparation. Oper Dent 40: 524-532. [Crossref]

3. Cekic-Nagas I, Ergun G, Egilmez F, Vallittu PK, Lassila LV (2016) Micro-shear bond strength of different resin cements to ceramic/glass-polymer CAD-CAM block materials. J Prosthodont Res 60: 265-273. [Crossref]

4. Lung CY, Matinlinna JP (2012) Aspect of silane coupling agents and surface conditioning in dentistry: an overview. Dent Mater 28: 467-477. [Crossref]

5. Bajraktarova-Valjakova E, Grozdanov A, Guguvcevski L, Korunoska-Stevkovska V, Kapusevska B, et al. (2018) Acid etching as surface treatment method for luting of glass-ceramic restorations, part 1: acids, application protocol and etching effectiveness Macedonian. Open Access Maced J Med Sci 6: 568-573. [Crossref]

6. Menees TS, Lawson NC, Beck PR, Burgess JO (2014) Influence of particle abrasion or hydrofluoric acid etching on lithium disilicate flexural strength. $J$ Prosthet Dent 112: 1164-1170. [Crossref]

7. Guarda GB, Correr AB, Gonçalves LS, Costa AR, Borges GA, et al. (2013) Effects of surface treatments, thermocycling, and cyclic loading on the bond strength of a resin cement bonded to a lithium disilicate glass ceramic. Oper Dent 38: 208-217. [Crossref]

8. Della Bona A, Anusavice KJ (2002) Microstructure, composition, and etching topography of dental ceramics The International. Int J Prosthodont 15: 159-167. [Crossref]

9. Ho GW, MatinlinnaJP (2011) Insights on ceramics as dental materials. Part II: Chemical Surface Treatments. Silicon 3: 117-123.

10. Della Bona A, Anusavice KJ, Hood JA (2002) Effect of ceramic surface treatment on tensile bond strength to a resin cement. Int J Prosthodont 15: 248-253. [Crossref]

11. Volkel T, Braziulis E (2015) Monobond Etch \& Prime, Scientific Documentation.

12. Román-Rodríguez JL, Perez-Barquero JA, Gonzalez-Angulo E, Fons-Font A, BustosSalvador JL (2017) Bonding to silicate ceramics: Conventional technique compared with a simplified technique. J Clin Exp Dent 9: e384-e386. [Crossref]

13. El-Damanhoury HM, Gaintantzopoulou MD (2018) Self-etching ceramic primer versus hydrofluoric acid etching: Etching efficacy and bonding performance. J Prosthodont Res 62: 75-83. [Crossref]

14. Prado M, Prochnow C, Marchionatti AME, Baldissara P, Valandro LF, et al. (2018) Ceramic Surface Treatment with a Single-component Primer: Resin Adhesion to Glass Ceramics. J Adhes Dent 20: 99-105. [Crossref]

15. Lopes GC, Perdigão J, Baptista D, Ballarin A (2018) Does a self-etching ceramic primer improve bonding to lithium disilicate ceramics? Bond strengths and FESEM analyses. Oper Dent 44: 210-218. [Crossref]

16. Murillo-Gómez F, Palma-Dibb RG, De Goes MF (2018) Effect of acid etching on tridimensional microstructure of etchable CAD/CAM materials. Dent Mater 34: 944955. [Crossref]
17. Lyann SK, Takagaki T, Nikaido T, Uo M, Ikeda M, et al. (2018) Effect of Different Surface Treatments on the Tensile Bond Strength to Lithium Disilicate Glass Ceramics. $J$ Adhes Dent 20: 261-268. [Crossref]

18. Özcan C, Hasirci N (2008) Evaluation of surface free energy for PMMA films. Journal of Applied Polymer Science 108: 438-446.

19. Blatz MB, Sadan A, Kern M (2003) Resin-ceramic bonding: a review of the literature. J Prosthet Dent 89: 268-274. [Crossref]

20. Chen L, Suh BI, Brown D, Chen X (2012) Bonding of primed zirconia ceramics: evidence of chemical bonding and improved bond strengths. Am J Dent 25: 103-108. [Crossref]

21. Panah FG, Rezai SM, Ahmadian L (2008) The influence of ceramic surface treatment on the micro-shear bond strength of composite resin to IPS Empress 2. J Prosthodont 17: 409-414. [Crossref]

22. Nagai T, Kawamoto Y, Kakehashi Y, Matsumura H (2005) Adhesive bonding of a lithium disilicate ceramic material with resin-based luting agents. J Oral Rehabil 32: 598-605. [Crossref]

23. Lin TJ, Antonelli JA, Yang DJ, Yasuda HK, Wang FT (1997) Plasma treatment of automotive steel for corrosion protection - a dry energetic process for coatings Progress in Organic Coatings 31: 351-361.

24. Yuan W, van Ooij WJ (1997) Characterization of Organofunctional Silane Films on Zinc Substrates J Colloid Interface Sci 185: 197-209. [Crossref]

25. Underhill PR, Goring G, DuQuesnay DL (1998) The drying of 3-glycidoxypropyltrimethoxy silane. Applied Surface Science 134: 247-253.

26. Bayle MA, Nasr K, Grégoire G, Sharrock P (2008) Acrylophosphonic acid reactivity with calcium ions and biological apatite. Dent Mater 24: 386-391. [Crossref]

27. Stawarczyk B, Hristova E, Sener B, Roos M, Edelhoff D, et al. (2014) Effect of hydrofluoric acid etching duration on fracture load and surface properties of three CAD/CAM glass-ceramics. Oral Health and Dental Management 13: 1131-1139.

28. Sriamporn T, Thamrongananskul N, Busabok C, Poolthong S, Uo M, et al. (2014) Dental zirconia can be etched by hydrofluoric acid. Dent Mater J 33: 79-85. [Crossref]

29. Ramakrishnaiah R, Alkheraif AA, Divakar DD, Matinlinna JP, Vallittu PK (2016) The effect of hydrofluoric acid etching duration on the surface micromorphology, roughness, and wettability of dental ceramics. Int J Mol Sci 17: 822. [Crossref]

30. Kalavacharla V, Lawson N, Ramp L, Burgess J (2014) Influence of etching protocol and silane treatment with a universal adhesive on lithium disilicate bond strength. Oper Dent 40: 372-378. [Crossref]

31. Lanza MDS, Rodrigues Lanza FJS, Manso AP, Matinlinna JP, Carvalho RM (2018) Innovative surface treatments for improved ceramic bonding: lithium disilicate glass ceramic. International Journal of Adhesion and Adhesives 82: 60-66.

32. Monobond Etch \& Prime Material Safety Data Sheet 21/09/2016 version.

33. Sattabanasuk V, Charnchairerk P, Punsukumtana L, Burrow MF (2017) Effects of mechanical and chemical surface treatments on the resin-glass ceramic adhesion properties. J Investig Clin Dent 8. [Crossref]

34. Peumans M, Hikita K, De Munck J, Van Landuyt K, Poitevin A, et al. (2007) Effects of ceramic surface treatments on the bond strength of an adhesive luting agent to CADCAM ceramic. J Dent 35: 282-288. [Crossref]

35. Blatz MB, Sadan A, Maltezos C, Blatz U, Mercante D, et al. (2004) In vitro durability of the resin bond to feldspathic ceramics. Am J Dent 17: 169-172. [Crossref]

36. El Zohairy AA, De Gee AJ, Hassan FM, Feilzer AJ (2004) The effect of adhesives with various degrees of hydrophilicity on resin ceramic bond durability. Dent Mater 20: 778-787. [Crossref]

37. Damia C, Sarda S, Deydier E, Sharrock P (2006) Study of two hydroxyapatite/ poly(alkoxysilane) implant coatings Surface \& Coatings Technology 201: 3008-3015.

Copyright: (C2019 Grégoire G. This is an open-access article distributed under the terms of the Creative Commons Attribution License, which permits unrestricted use, distribution, and reproduction in any medium, provided the original author and source are credited. 